\title{
Testosterone Deficiency, CTCAE
}

National Cancer Institute

\section{Source}

National Cancer Institute. Testosterone Deficiency, CT CAE. NCI Thesaurus. Code C143195.

A disorder characterized by low testosterone. 